\title{
Impulsive antisociality and executive control problems: evidence from go/no-go and stop-signal tasks
}

\author{
Jarosław M. Michałowski ${ }^{1 \cdot A, C, D, E, F, G}$, Dawid Droździel ${ }^{1 \cdot A, B, C, D, E, F}$, Michat Harciarek ${ }^{2 \cdot D, E}$ \\ 1: Faculty of Psychology, University of Warsaw, Warsaw, Poland \\ 2: Institute of Psychology, University of Gdansk, Gdansk, Poland
}

BACKGROUND

People with impulsive-antisocial traits may engage in unplanned behaviors that reduce their efficiency and may even result in harm to self and others. The present study aimed to investigate the relationship between executive control functions and impulsive antisociality, as assessed with the Psychopathic Personality Inventory (PPI). Using go/no-go and stop-signal paradigms, we examined whether healthy participants with high impulsive-antisocial traits would show delayed response inhibition and error monitoring deficits when compared to those reporting low levels of impulsive antisociality.

\section{PARTICIPANTS AND PROCEDURE}

A total of 26 participants were recruited from different Warsaw universities based on the Impulsive Antisociality subscale scores of the PPI. Subjects scoring in the first quartile were assigned to the low and those with a score in the fourth quartile were selected for the high impulsivity group. All participants were tested with go/no-go and stop-signal tasks that were executed in a random order.
RESULTS

Higher levels of impulsive-antisocial traits were associated with poorer executive control. In particular, high impulsive-antisocial individuals demonstrated reduced post-error slowing in response to go stimuli following an error and took longer to respond to the stop signal than the control group. The two groups did not differ in their performance accuracy.

\section{CONCLUSIONS}

The study extends previous findings regarding the relationship between impulsivity and executive control showing that non-clinical impulsive antisociality results in decreased conflict detection ability and delayed response inhibition. These problems may result in reduced executive effectiveness in everyday life situations.

\section{KEY WORDS}

impulsive antisociality; executive control; Psychopathic Personality Inventory (PPI); go/no-go task; stop-signal task

CORRESPONDING AUthor - Jarosław M. Michałowski, Faculty of Psychology, University of Warsaw, 5/7 Stawki Str.,

00-183 Warsaw, Poland, e-mail: jmichalowski@psych.uw.edu.pl

authors' contribution - A: Study design · B: Data collection · C: Statistical analysis · D: Data interpretation ·

E: Manuscript preparation · F: Literature search · G: Funds collection

to CITE THIS ARTICLE - Michałowski, J. M., Droździel, D., \& Harciarek, M. (2015). Impulsive antisociality and executive

control problems: evidence from go/no-go and stop-signal tasks. Current Issues in Personality Psychology, 3(1), 36-41. RECEIVED 01.11.2014 · REVIEWED 12.02.2015 · ACCEPTED 09.03.2015 · PUBLISHED 27.03.2015 


\section{BACKGROUND}

Psychopathy is marked by significant behavioral deviancy as well as coexisting emotional and interpersonal characteristics. Modern conceptualizations and measures of psychopathy have been motivated by Cleckley's account based on his experience with clinical psychopaths (Cleckley, 1976). Cleckley described several characteristics of the psychopathic personality, inspiring researchers to consider psychopathy as a multidimensional construct. Indeed, factor analytic studies performed with the instruments for the assessment of psychopathy supported this multidimensional view. For example, the data structure of Hare's Psychopathy Checklist (PCL-R) (Hare, 2003), designed for forensic populations, and the Psychopathy Personality Inventory (PPI) (Lilienfeld \& Andrews, 1996) for measuring psychopathy in noncriminal samples was repeatedly observed to be best reflected by a two-factor solution (Benning, Patrick, Hicks, Blonigen, \& Krueger, 2003; Hare, 1991, 2003; Harpur, Hare, \& Hakstian, 1989; Lilienfeld \& Andrews, 1996). One of these factors included items assessing affective-interpersonal deficits, e.g. shallow affect, reduced fear-reactivity, lack of empathy and close relationships. The second factor contained items describing impulsive-antisocial features, e.g. problems with planning/foresight, demand for immediate gratification, and poor emotional and behavioral control. Contemporary research on psychopathy tries to elucidate affective, cognitive and behavioral phenomena associated with these two dimensions of psychopathy. In the cognitive and behavioral domains, high levels of psychopathic traits have been shown to be associated with executive difficulties, poor executive control in particular. Some studies have suggested that deficits in executive control may be linked to psychopathy-associated impulsivity (Finn, Justus, Mazas, \& Steinmetz, 1999; Stanford, Greve, \& Gerstle, 1997; Villemarette-Pittman, Stanford, \& Greve, 2003).

In order to characterize specific cognitive functions contributing to executive control, recent studies have begun to systematically use reaction time tasks requiring differentiation between execution and inhibition trials, such as go/no-go or stop-signal tasks. In the go/no-go task participants are presented with a series of different stimuli and are instructed to respond to one stimulus type while ignoring others. In the stop-signal paradigm participants perform a similar go/no-go task but are also required to perform a stop task at the same time. The stop task occurs in $25 \%$ of go trials and involves the presentation of a stop signal that informs the subject to inhibit his/her response to the go trial. In the most common version of the stop-signal task, the time interval between the go and the stop signal varies as a function of subjects' performance. That is, with successful inhibition this interval will increase, and if the person reacts to a go stimulus despite the presence of a stop signal, at the next attempt the time between the go and the stop signal will be reduced. This procedure enables one to design an appropriate stop-signal delay in which the person inhibits $50 \%$ of the go trials. Both tasks allow assessment of the attention-related response latency (reaction time) as well as the error-monitoring accuracy. The go/no-go task is also suitable to measure the process of conflict detection, as indexed by a post-error slowing (PES), that is, a typical slowdown in reaction time (RT) in trials following an error (Rabbitt, 1966). Moreover, as already mentioned, both tasks are also suitable to observe the mechanism of response inhibition. The go/ no-go procedure enables one to assess the effectiveness of prepotent response inhibition, whereas the stop-signal task allows one to measure the accuracy and latency of the ongoing response inhibition. The stop-signal task involves the response reengagement process and requires higher attentional capacity.

Using go/no-go or stop-signal tasks, previous studies found response inhibition and conflict detection deficits in high impulsive individuals, such as those with attention deficit hyperactivity disorder (ADHD) (Schachar \& Logan, 1990), alcoholism (Finn, Mazas, Justus, \& Steinmetz, 2002; Lawrence, Luty, Bogdan, Sahakian, \& Clark, 2009; Noël et al., 2007) and obesity (Nederkoorn, Havermans, Roefs, Smulders, \& Jansen, 2006). Considering differential correlates of the two dimensions of psychopathy, impaired go/no-go and stop-signal task performance should also be expected in individuals scoring highly on the impulsive antisociality factor. Supporting this assumption, Wilkowski and Robinson (2008) showed deficient post-error slowing in a series of choice reaction time tasks involving word categorization in undergraduate students with impulsive-antisocial traits, as measured with the Levenson Self-Report Psychopathy Scales (LSRPS) (Levenson, Kiehl, \& Fitzpatrick, 1995). However, this finding should be treated with caution because the LSRPS does not accurately cover the impulsive-antisocial dimension, as it was proposed on the basis of Cleckley's account (Lynam, Whiteside, \& Jones, 1999). In fact, the LSRPS also show moderate to large correlations with the other interpersonal-affective factor (Hare, 2003; Levenson et al., 1995). Recently, using the Multidimensional Personality Questionnaire (MPQ) (Tellegen \& Waller, 1994), Heritage and Benning (2013) demonstrated deficits in the processing of peripheral cues in high impulsive-antisocial individuals performing a lexical decision stop-signal task. Specifically, high impulsive individuals showed reduced lexical decision and stop-signal inhibition accuracy and longer stop-signal reaction times (SSRTs), indicating poor error monitoring and problems in stopping the ongoing action in response to the peripheral stop cues in this group. 
The present study was designed to compare cognitive processes involved in executive control between high and low impulsive-antisocial individuals. In order to achieve this aim, we extended previous studies by combining the standard visual go/no-go with stop-signal tasks in order to assess specific cognitive functions contributing to executive control, such as the post-error conflict detection and the effectiveness of prepotent response inhibition (go/no-go task), the effectiveness and latency of ongoing response inhibition (stop-signal task) as well as the response activation latency (both tasks). Specifically, similarly to some previous research (see Heritage \& Benning, 2013; Wilkowski \& Robinson, 2008), we expected that, when compared with low impulsive-antisocial individuals, high impulsive-antisocial participants would present with reduced post-error slowing (PES) and error-monitoring accuracy as well as delayed inhibition of ongoing responses. Of note, however, in contrast to the studies by Wilkowski and Robinson (2008) and Heritage and Benning (2013), we selected our participants based on the PPI, an instrument that has been shown to be most appropriate for measuring the psychopathy construct in non-incarcerated samples (Lilienfeld \& Andrews, 1996). Moreover, it has been shown that this tool can successfully differentiate between impulsive antisociality and interpersonal-affective dimensions of psychopathy that correspond to the two factors of the PCL-R intended to measure prisoner samples (Poythress, Edens, \& Lilienfeld, 1998; Benning et al., 2003).

\section{PARTICIPANTS AND PROCEDURE}

\section{PARTICIPANTS}

A total of 26 participants were selected from a questionnaire screening of 162 students of different Warsaw universities. At the time of recruitment all participants completed the Polish version of the PPI (Lilienfeld \& Andrews, 1996; Groth \& Cierpiałkowska, 2012). Subjects scoring in the first quartile on the PPI Impulsive Antisociality subscale ( $<140$ points) were assigned to the low impulsivity group $(N=12$, 11 females, 1 male), and those with a score in the fourth quartile ( $>166$ points) were assigned to the high impulsivity group ( $N=14,10$ females, 4 males $)$.

\section{PROCEDURE}

PsychoPy (Peirce, 2007, 2009) and STOP-IT (Verbruggen, Logan, \& Stevens, 2008) software was used to prepare and run the experiment. Subjects responded using the standard QWERTY keyboard. Stimuli were presented on a CRT monitor with a refresh rate of $60 \mathrm{~Hz}$. A sound signal $(750 \mathrm{~Hz}, 75 \mathrm{~ms})$ was emitted by the audio system consisting of an amplifier and two speakers mounted in front of the subject.

The study included the go/no-go and stop-signal tasks that were executed in a random order. Subjects were informed that the purpose of the study was to measure the reaction time to visual stimuli. The go/ no-go study was divided into two series, each consisting of 64 trials, preceded by the presentation of a fixation cross. Subjects were instructed to react to the occurrence of a letter "A" by pressing a space key and to do nothing in response to a letter "P". There were 48 go and 16 no-go letters that were presented in a randomized order for $250 \mathrm{~ms}$ with an inter-trial interval ranging from 3.50 to $4.50 \mathrm{~s}$. The stop-signal experiment consisted of 32 practice trials followed by two series of 64 experimental trials. Each trial consisted of the presentation of a square or a circle that was preceded by a fixation point $(250 \mathrm{~ms})$ and followed by a 2.5-second inter-trial interval. Subjects were briefed to press the "C" key in response to the occurrence of the square and the "/" key for the circle or to inhibit the reaction if they heard an auditory signal that was presented after $25 \%$ of the go stimuli. Initially the stop signal was presented $250 \mathrm{~ms}$ after the onset of the go stimulus and was then adjusted continuously: the time interval between the go and stop stimuli (stop-signal delay) increased by $50 \mathrm{~ms}$ when the subject successfully inhibited his/her response and decreased by $50 \mathrm{~ms}$ when inhibition was unsuccessful. The study protocol was approved by the local ethics committee.

\section{DATA ANALYSIS}

In the case of the go/no-go task, we analyzed mean reaction time in all go trials, the number of false no-go responses as well as the post-error slowing (PES), i.e. the difference between the mean response time to the go stimuli that occurred after a false no-go response and the mean response time to all other go stimuli. In the case of the stop-signal task, the analysis included mean reaction time on no-signal trials, errors and stop-signal reaction time (SSRT). The SSRT was computed by subtracting the mean stop-signal delay (SSD) from the mean reaction time for all trials that were not followed by a stop signal.

IBM SPSS Statistics v. 21. software was used for statistical data analysis. The data analysis ANALYZE-IT software from the STOP-IT program was used for SSRT estimation. Intergroup comparisons were computed using unpaired two-sample $t$-tests.

\section{RESULTS}

\section{$\mathrm{GO} / \mathrm{NO}-\mathrm{GO}$}

Low impulsive subjects responded to no-go trials (false alarms) with an average of $15.10 \%(S D=13.00 \%)$ 
Executive control problems in impulsive antisociality

Table 1

Go/no-go and stop-signal response time data [ms] from high and low impulsive-antisocial individuals

\begin{tabular}{ccccc}
\hline \multirow{2}{*}{ Group } & \multicolumn{4}{c}{ Task } \\
\cline { 2 - 5 } & \multicolumn{3}{c}{ Go/no-go task } & Stop-signal task \\
\cline { 2 - 5 } & All go trials & Post-error slowing & All non-signal trials & SSRT \\
& $M(S D)$ & $M(S D)$ & M (SD) & $M(S D)$ \\
\hline Low & $353(36)$ & $21.10(34.4)$ & $518.20(113.60)$ & $280.50(44.50)$ \\
High & $363(52)$ & $-19.30(56.9)$ & $513.60(95.60)$ & $327.00(58.90)$ \\
\hline
\end{tabular}

Note. SSRT - stop-signal reaction time

and high impulsive subjects with an average of $18.50 \%$ $(S D=12.50 \%)$. The two-tailed $t$-test revealed no significant differences between the groups for the amount of these errors, $t(24)=0.68$, n.s. There was a significantly greater PES in the low when compared to the high impulsivity group, $t(23)=2.07, p=.050$ (see Table 1 ). However, the two groups did not significantly differ in the mean reaction time in all go trials, $t(24)=0.57$.

\section{STOP SIGNAL}

Regarding the go stimulus categorization, low impulsivity subjects made an average of $1.33 \%$ errors $(S D=1.21 \%)$, whereas those from the high impulsivity group made an average of $1.99 \%$ errors $(S D=1.91 \%)$, and these differences were not statistically significant, $t(24)=1.03$, n.s. Also differences between the low and high impulsivity group in mean reaction time in no-signal trials were not statistically significant, $t(24)=0.11$, n.s. However, statistically significant differences were observed when the results of the SSRT were compared between low and high impulsivity subjects, $t(24)=2.24, p=.035$, showing that high impulsive participants, in comparison to those with low impulsiveness, needed more time to stop their reaction (see Table 1).

\section{DISCUSSION}

In the present study, go/no-go and stop-signal reaction time tasks were used to investigate executive control functions in participants with high and low levels of impulsive-antisocial traits, as measured with the PPI (Lilienfeld \& Andrews, 1996). Supporting the assumption about problems with executive control in high impulsivity, our study showed that, when compared to low impulsive-antisocial individuals, high impulsive-antisocial subjects present with reduced post-error slowing and delayed response inhibition, as revealed by the go/no-go task and the stop-signal task respectively. At the same time, the two groups did not differ in the number of errors or in the time needed for response activation.
Monitoring and adjusting errors enables one to regulate behavior and to pursue personal goals. According to previous studies, people tend to slow their reaction time in trials following response errors, an effect that has been proposed to reflect increased cautiousness in responding that helps to avoid further errors (Botvinick, Braver, Barch, Carter, \& Cohen, 2001; Bresin, Finy, Spraque, \& Verona, 2014; Dutilh et al., 2012). In the present study, this post-error slowing was found to be reduced in high impulsive-antisocial individuals, indicating that this group might be less able to notice errors and/or to take them seriously. Supporting this finding, an ERP study performed by Heritage and Benning (2013) showed that errors in responding elicit significantly lower error-related negativity (ERN) in people with high when compared to those with low impulsive-antisocial traits. This effect indicates reduced activation of the frontal brain structures responsible for the detection of conflict between the task performance and the goals of the task (Fabiani, Gratton, \& Coles, 2000).

Previous studies revealed that people sensitive to frustration of their goals and those with low executive control respond with increased anger and/or higher tense arousal when confronted with frustration-generating situations (Sprague, Verona, Kalkhoff, \& Kilmer, 2011; Zajenkowska, Zajenkowski, \& Jankowski, 2014). In antisocially impulsive people the anticipation or confrontation with frustration-generating situations may, thus, trigger stronger negative emotions amplifying emotional and behavioral control deficits. These deficits may again impede the achievement of personal goals and intensify negative emotions. This vicious circle may explain some behavioral and emotional deficits in populations characterized by increased impulsivity and/or impulsive antisociality (e.g. antisocial personality disorder, behavioral and substance addictions, procrastination). As a caveat it has to be noted that despite reduced post-error slowing, high impulsive-antisocial students who participated in our study were able to compensate for their deficits, resulting in similar performance accuracy as the control group. Future studies might help to determine whether error 
processing problems observed in people with high impulsive-antisocial traits would lead to a lack of planfulness and foresight as well as behavior regulation problems in everyday life situations.

Apart from the process of error monitoring, effective behavior regulation requires inhibition of prepotent and ongoing courses of action. Supporting previous studies performed with clinical samples (Lawrence et al., 2009; Nederkoorn et al., 2006; Schachar \& Logan, 1990) as well as high and low impulsive students divided according to their impulsivity subscale scores of the Eysenck Personality Inventory (Eysenck \& Eysenck, 1969; Logan, Schachar, \& Tannock, 1997), the present data indicate that greater levels of impulsive-antisocial traits are associated with increased stop-signal delay. That is, people with high impulsive antisociality took longer than the non-impulsive control group to respond to the stop signal. This finding supports the assumption that impulsive-antisocial traits result in difficulties in inhibitory processing. Similar to the go/no-go task, the stop-signal data did not reveal differences in the number of errors between high and low impulsive-antisocial subjects. Again, this finding suggests that the non-clinical impulsive individuals are able to inhibit their responses, even though they may be less effective or efficient than non-impulsive people. Furthermore, our data indicate that high and low impulsive-antisocial individuals do not differ in the response time to go stimuli during the stop-signal and go/no-go tasks. This seems consistent with findings by Logan et al. (1997) as well as Nederkoorn et al. (2006), showing that deficits observed in high impulsive samples during reaction time tasks requiring one to differentiate between execution and inhibition trials result from decreased inhibition ability rather than from increased impetus to respond.

The link between impulsivity and longer stop-signal reaction times as well as reduced post-error slowing has been established using different self-report measures of impulsivity, such as the impulsivity subscale of the Eysenck Personality Inventory (Eysenck \& Eysenck, 1969; Logan et al., 1997), the Levenson Self-Report Psychopathy Scales (Levenson et al., 1995; Wilkowski \& Robinson, 2008), and the Multidimensional Personality Questionnaire (Tellegen \& Waller, 1994; Heritage \& Benning, 2013). Response inhibition and conflict detection deficits have been observed in high impulsive clinical samples, such as ADHD (Schachar \& Logan, 1990), alcoholism (Finn et al., 2002; Lawrence et al., 2009; Noël et al., 2007) and obesity (Nederkoorn et al., 2006). In this respect, the present study proves the validity of the Impulsive Antisociality subscale of the PPI (Lilienfeld \& Andrews, 1996) that was developed to measure impulsive-antisocial and interpersonal-affective psychopathy traits in noncriminal samples.

\section{CONCLUSIONS}

The present study supports and extends previous evidence for decreased executive control abilities in high impulsive-antisocial individuals. Specifically, non-clinically increased impulsive antisociality resulted in decreased conflict detection ability and delayed response inhibition. Even though antisocially impulsive individuals did not show decreased performance accuracy in the present study, the observed problems with executive control may potentially contribute to decreased efficiency or effectiveness in this group.

This study was supported by a grant from the $\mathrm{Na}$ tional Science Centre (Narodowe Centrum Nauki, NCN) to the first author, 2011/03/D/HS6/05951.

\section{References}

Benning, S. D., Patrick, C. J., Hicks, B. M., Blonigen, D. M., \& Krueger, R. F. (2003). Factor structure of the Psychopathic Personality Inventory: Validity and implications for clinical assessment. Psychological Assessment, 15, 340-350.

Botvinick, M. M., Braver, T. S., Barch, D. M., Carter, C. S., \& Cohen, J. D. (2001). Conflict monitoring and cognitive control. Psychological Review, 108, 624-652.

Bresin, K., Finy, M. S., Spraque, J., \& Verona, E. (2014). Response monitoring and adjustment: differential relations with psychopathic traits. Journal of $A b$ normal Psychology, 123, 634-649.

Cleckley, H. (1976). The mask of sanity ( $5^{\text {th }}$ ed.). St Louis, MO: Mosby.

Dutilh, G., Vandekerckhove, J., Forstmann, B. U., Keuleers, E., Brysbaert, M., \& Wagenmakers, E. (2012). Testing theories of post-error slowing. Attention, Perceptions, and Psychophysics, 74, 454-465.

Eysenck, H. J., \& Eysenck, S. B. (1969). Personality structure and measurement. San Diego: Knapp.

Fabiani, M., Gratton, G., \& Coles, M. G. H. (2000). Event-related brain potentials. In: J. T. Cacioppo, L. G. Tassinary, \& G. G. Berntson (eds.), Handbook of psychophysiology (2 ${ }^{\text {nd }}$ ed., pp. 53-84). New York: Cambridge University Press.

Finn, R. R., Justus, A., Mazas, C., \& Steinmetz, J. E. (1999). Working memory, executive processes and the effects of alcohol on Go/no-go learning: testing a model of behavioral regulation and impulsivity. Psychopharmacology, 146, 465-472.

Finn, R. R., Mazas, C., Justus, A., \& Steinmetz, J. E. (2002). Early-onset alcoholism with conduct disorder: go/no go learning deficits, working memory capacity, and personality. Alcoholism, Clinical and Experimental Research, 26, 186-206.

Groth, J., \& Cierpiałkowska, L. (2012). Pięcioczynnikowy model osobowości a profile psychopatii w gru- 
pie nieprzestępczej [The five-factor model of personality and profiles of psychopathy in a non criminal sample]. Czasopismo Psychologiczne, 18, 107-118.

Hare, R. D. (1991). Manual for the Revised Psychopathy Checklist. Toronto, ON, Canada: Multi-Health Systems.

Hare, R. D. (2003). The Hare Psychopathy Checklist - Revised ( $2^{\text {nd }}$ ed). Toronto, ON, Canada: MultiHealth Systems.

Harpur, T. J., Hare, R. D., \& Hakstian, A. R. (1989). Two-factor conceptualization of psychopathy: Construct validity and assessment implications. Psychological Assessment. Journal of Consulting and Clinical Psychology, 1, 6-17.

Heritage, A. J., \& Benning, S. D. (2013). Impulsivity and response modulation deficits in psychopathy: Evidence from the ERN and N1. Journal of Abnormal Psychology, 122, 215-222.

Lawrence, A. I., Luty, I., Bogdan, N. A., Sahakian, B. I., \& Clark, L. (2009). Impulsivity and response inhibition in alkohol dependence and problem gamblings. Psychopharmacology, 207, 163-172.

Levenson, M. R., Kiehl, K. A., \& Fitzpatrick, C. M.(1995). Assessing psychopathic attributes in a noninstitutional population. Journal of Personality and Social Psychology, 68, 151-158.

Lilienfeld, S. O., \& Andrews, B. P. (1996). Development and preliminary validation of a self report measure of psychopathic personality traits in noncriminal populations. Journal of Personality Assessment, 66, 488-524.

Logan, G. D., Schachar, R. J., \& Tannock, R. (1997). Impulsivity and inhibitory control. Psychological Science, 8, 60-64.

Lynam, D. R., Whiteside, S., \& Jones, S. (1999). Self-reported psychopathy: A validation study. Journal of Personality Assessment, 73, 110-132.

Nederkoorn, C., Havermans, H., Roefs, A., Smulders, F. T. Y., \& Jansen, A. (2006). Impulsivity in obese women. Appetite, 47, 253-256.

Noël, X., Van der Linden, M., d'Acremont, M., Bechara, A., Dan, B., Hanak, C., \& Verbanck, P. (2007). Alcohol cues increase cognitive impulsivity in individuals with alcoholism. Psychopharmacology, 192, 291-298.

Peirce, J. W. (2007). PsychoPy - Psychophysics software in Python. Journal of Neuroscience Methods, 162, 8-13.

Peirce, J. W. (2009). Generating stimuli for neuroscience using PsychoPy. Frontiers in Neuroinformatics, 2, 10.

Poythress, N. G., Edens, J. F., \& Lilienfeld, S. O. (1998). Criterion-related validity of the Psychopathic Personality Inventory in a prison sample. Psychological Assessment, 10, 426-430.

Rabbitt, P. M. A. (1966). Errors and error-correction in choice-response tasks. Journal of Experimental Psychology, 71, 264-272.
Schachar, R., \& Logan, G. D. (1990). Impulsivity and inhibitory control in normal development and childhood psychopathology. Developmental Psychology, 26, 710-720.

Sprague, J., Verona, E., Kalkhoff, W., \& Kilmer, A. (2011). Moderators and mediators of the stress-aggression relationship: executive function and state anger. Emotion, 11, 63-73.

Stanford, M. S., Greve, K. W., \& Gerstle, J. E. (1997). Neuropsychological correlates of self-reported aggression in a college sample. Personality and Individual Differences, 23, 961-965.

Tellgen, A., \& Waller, N. G. (1994). Exploring personality through test construction: Development of the Multidimensional Personality Questionnaire. In: S. R. Briggs, \& J. C. Check (eds.), Personality measures: Development and Evaluation (Vol. 1), (pp. 133-161). Greenwich: JAI.

Verbruggen, F., Logan, G. D., \& Stevens, M. A. (2008). STOP-IT: Windows executable software for the stop-signal paradigm. Behavior Research Methods, 40, 479-483.

Villemarette-Pittman, N. R., Stanford, M. S., \& Greve, K. W. (2002). Language and executive function in self-reported impulsive aggression. Personality and Individual Differences, 34, 1533-1544.

Wilkowski, B. M., \& Robinson, M. D. (2008). Putting the brakes on antisocial behavior: Secondary psychopathy and post-error adjustments in reaction time. Personality and Individual Differences, 44, 1807-1818.

Zajenkowska, A., Zajenkowski, M., \& Jankowski, K. S. (in press). The relationship between mood experienced during an exam, proneness to frustration and neutroticism. Learning and Individuals Differences. 